\title{
Early ductal shunting and intraventricular haemorrhage in ventilated preterm infants
}

Department of Neonatal Medicine, King George V Hospital, Part of Royal Prince Alfred Hospital, Missenden Road, Camperdown, Sydney, NSW 2050, Australia. N Evans

M Kluckow

Correspondence to: Dr Nick Evans.

\begin{abstract}
Aim-To establish if there is an association between early cardiovascular adaptation and intraventricular haemorrhage (IVH).

Methods-One hundred and seventeen ventilated preterm infants (mean gestational age 27 weeks, mean birthweight $993 \mathrm{~g}$ ) were studied echocardiographically within the first 36 hours. Measurements included right (RVO) and left ventricular outputs (LVO), ductus arteriosus (PDA) and atrial shunt diameter using colour Doppler and pulsed Doppler direction and velocity of both shunts. Clinical variables collected over the first 24 hours included use of antenatal steroids, respiratory severity, and mean blood pressure. Cerebral ultrasound scans were reported by a radiologist blinded to clinical and echocardiographic data.

Results-Antenatal steroids (two doses) had been given to $73 \%$ of the 86 infants with no IVH compared with $48 \%$ of the 21 infants with grades 1 and 2 IVH, and just $10 \%$ of 10 babies with grades 3 and 4 $(\mathbf{P}<0.05)$. Both groups with IVH had significantly larger PDA diameters than the group with no IVH. Infants with grades 3 and 4 IVH had significantly lower RVO than the other infants. These differences were more pronounced when only infants with definite late IVH were analysed. Logistic regression analysis showed lack of antenatal steroids and larger PDA diameters were significantly associated with any grade of IVH and lack of antenatal steroids; lower RVO was significantly associated with grades 3 and 4 IVH. Conclusions-Larger early PDA shunts, lower RVO, and lack of antenatal steroids were significantly associated with IVH. (Arch Dis Child 1996;75:F183-F186)
\end{abstract}

Keywords: intraventricular haemorrhage, patent ductus arteriosus, cardiac output, premature infant.

The haemodynamic basis of intraventricular haemorrhage (IVH) remains unclear. Both the association with early hypotension ${ }^{1-3}$ and studies of cerebral blood flow $^{45}$ suggest that cerebral hypoperfusion is an important antecedent risk factor. Few studies of cerebral blood flow have encompassed the driving force behind that flow, the cardiovascular system. An association between patent ductus arteriosus (PDA) shunting and IVH has been suggested ${ }^{6}$ but these studies have not embraced the wide range of the importance of shunting through the PDA in the early postnatal period, when most IVH occur. ${ }^{7}$

We have shown that an assessment of both atrial and PDA shunt size can be derived from the respective colour Doppler shunt diameter. ${ }^{89}$ We used this and other echocardiographic measures to highlight the complexity of early preterm cardiac haemodynamics in a cohort of 120 ventilated preterm infants. ${ }^{10}$ Low ventricular outputs are a common early finding and are associated with high ventilatory pressures and large left to right PDA and atrial shunts which "steal" blood from the systemic circulation, even in the early postnatal period. ${ }^{10}$

We hypothesised that there is an association between these early cardiovascular changes and IVH. The aim of this analysis was to examine if there were any significant associations, in this same group of preterm infants, between our early echocardiographic measures, other perinatal variables, and the occurrence of IVH.

\section{Methods}

Preterm infants with a birthweight of less than $1500 \mathrm{~g}$ and respiratory problems likely to require mechanical ventilation for more than 24 hours were selected for echocardiographic study. The infants were studied over two 12 month periods which began, respectively, in February 1992 and June 1993. Echocardiography was performed at a mean of 19 hours of age (range 7-31 hours).

Echocardiographic data collection was done using an Acuson 128/XP10 ultrasound machine with a $7 \mathrm{MHz}$ transducer incorporating colour flow, pulsed wave, and continuous wave Doppler. Structural normality of the heart was established on the initial scan. A videotape of the scan was made and measurements were done later. Echocardiographic measures included: right ventricular output (RVO); colour Doppler diameter and pulsed Doppler direction of any ductus arteriosus shunt; left ventricular output (LVO); colour Doppler diameter and pulsed Doppler direction of any interatrial shunt. The echocardiographic procedure and measurement protocol have been described before. ${ }^{10}$

Cerebral ultrasound scans were performed with a $7 \mathrm{MHz}$ transducer. All infants were scanned between the fourth and seventh postnatal day and then again on day 28 . These scans were recorded on to $x$-ray film and reported by a paediatric radiologist who was unaware of either the echocardiographic or clinical findings. These scans were used as the 
Table 1 Antenatal and demographic variables according to grade of IVH (values are medians and range or percentage)

\begin{tabular}{llll}
\hline & No IVH $(n=86)$ & $\begin{array}{l}\text { Grade 1/2 IVH } \\
(n=21)\end{array}$ & $\begin{array}{l}\text { Grade 3/4 IVH } \\
(n=10)\end{array}$ \\
\hline Gestation (weeks) & $27.5(24-34)$ & $26(24-30)$ & $27.5(26-29)$ \\
Birth weight (g) & $1027(512-1490)$ & $927(755-1370)$ & $937(755-1485)$ \\
Antenatal steroids (any) & $91 \% \ddagger$ & $76 \% \dagger$ & $50 \% \dagger \ddagger$ \\
Antenatal steroids $(\times 2)$ & $73 \% \dagger$ & $48 \% \dagger$ & $10 \% \dagger$ \\
Delivery by emergency & $53 \%$ & $38 \%$ & $50 \%$ \\
$\quad$ LSCS & $20 \%$ & $19 \%$ & $20 \%$ \\
Maternal hypertension & $8(2-10)$ & $8(4-10)$ & $7(4-9)$ \\
Apgar score at 5 minutes & $8(10)$ & \\
\hline
\end{tabular}

and $\ddagger$ mark significant differences between two groups, $P<0.05$. LSCS: lower segment caesarean section

primary outcome measure with respect to this study. Most infants (27 of 31 who developed IVH) had a cerebral ultrasound scan at the time of echocardiography which was interpreted by the echocardiographer (NE or MK) both of whom are experienced and trained in the interpretation of neonatal cerebral ultrasonography. As these early scans were not interpreted blinded, they were used in a secondary analysis of the timing of IVH relative to the echocardiogram.

IVH was classified into grades 1 to 4 according to the Papile classification. Grade 1: germinal matrix haemorrhage; grade 2 : with extension into the ventricles; grade 3: with ventricular dilatation; grade 4 : with intraparenchymal extension.

Antenatal variables recorded included maternal hypertensive disease, antenatal steroids (a complete course being defined as two doses 12 hours apart given before delivery) and type of delivery.

Postnatal variables recorded included averaged hourly measures of $\mathrm{FIO}_{2}$ and mean airway pressure (MAP) over the first 24 hours. The averaged hourly measures of mean blood pressure (MBP), the lowest recorded MBP, the percentage of time that the MBP was less than $30 \mathrm{~mm} \mathrm{Hg}$ and the variation in MBP (expressed as the standard deviation divided by the mean) were recorded for the first 24 hours. All blood pressure measurements were taken from intra-arterial catheters.

All ventilated infants were sedated with a morphine infusion at 20 to $40 \mu \mathrm{g} / \mathrm{kg} /$ hour. Muscle relaxation was not used routinely. Surfactant therapy was given as two doses of Exosurf, 12 hours apart, as rescue treatment to infants with radiological hyaline membrane disease and an $\mathrm{FIO}_{2}$ greater than 0.3. All infants given surfactant had received their first dose by the time of echocardiography. No infant had air leak syndrome at the time of echocardiography. Blood pressure was sup-

Table 2 Respiratory and cardiovascular support within first 24 hours according to grade of IVH (values are medians and range or percentage)

\begin{tabular}{|c|c|c|c|}
\hline & No IVH $(n=86)$ & $\begin{array}{l}\text { Grade } 1 / 2 I V H \\
(n=21)\end{array}$ & $\begin{array}{l}\text { Grade } 3 / 4 \text { IVH } \\
(n=10)\end{array}$ \\
\hline $\begin{array}{l}\text { Mean airway pressure (cm } \\
\mathrm{H}_{2} \mathrm{O} \text { ) }\end{array}$ & $7.9(4-13.8)$ & $8.0(5.5-14.2)$ & $9.1(6-13)$ \\
\hline Mean $\mathrm{FIO}_{2}$ & $0.44(0.21-1)$ & $0.48(0.26-0.84)$ & $0.46(0.25-0.89)$ \\
\hline Surfactant & $57 \%$ & $76 \%$ & $70 \%$ \\
\hline Inotropes & $26 \%$ & $24 \%$ & $30 \%$ \\
\hline Volume expanders & $29 \% \star$ & $38 \%$ & $60 \% \star \star$ \\
\hline Volume expanders $\mathrm{ml} / \mathrm{kg}$ & $10(7-56)$ & $10(10-58)$ & $15(10-18)$ \\
\hline
\end{tabular}

^ marks significant differences between two groups, $\mathrm{P}<0.05$. ported if the mean blood pressure fell consistently below the infant's gestation in weeks. Human albumin $(10 \mathrm{ml} / \mathrm{kg}$ of $5 \%)$ was given initially, followed by dopamine (or occasionally dobutamine at the clinician's discretion) at 10 $\mu \mathrm{g} / \mathrm{kg} / \mathrm{min}$, increasing in steps to a maximum of $20 \mu \mathrm{g} / \mathrm{kg} / \mathrm{min}$ if MBP did not improve. Further boluses of $5 \%$ albumin were given, at the attending clinician's discretion, if hypotension persisted. Of the 32 infants who were given inotropes, 31 were already receiving them at the time of echocardiography.

The study had the approval of the Royal Prince Alfred Hospital ethics committee and all infants were studied with the informed consent of their parents unless there was a clinical indication for echocardiography.

Statistics were performed with a PC software package (SPSS, Chicago, Illinois) using Mann Whitney U test and logistic regression. Significance was accepted at $P<0.05$.

\section{Results}

One hundred and forty one infants who met the study entry criteria were admitted to our nursery during the two 12 month study periods. Twenty one infants $(14 \%$ of total eligible infants) were not studied as neither investigator was available to perform a scan after they were born. Three babies were excluded because they died before IVH could be assessed as an outcome measure. The remaining 117 infants were incorporated into this analysis. They had a mean gestation of 27.3 weeks with a range from 24 to 33 weeks and a mean birthweight of $993 \mathrm{~g}$ (range 512 to $1490 \mathrm{~g}$ ). Of the 21 eligible babies not studied, three had grade $1 \mathrm{IVH}$ and two grade $2 \mathrm{IVH}$.

Infants were classified into three groups: those with no IVH $(n=86)$; those with grades 1 or 2 IVH $(n=21)$; and those with grades 3 or 4 IVH $(n=10)$. There were no significant differences in antenatal or demographic variables except in the proportion of each group who received a complete course of antenatal steroids (table 1). Seventy three per cent with no IVH received a complete course compared with just one $(10 \%)$ of the infants who developed a grade 3 or 4 IVH $(P<0.04)$. Infants with grade 3/4 IVH were more likely to be given plasma volume expanders in the first 24 hours of life than those without IVH $(\mathrm{P}<0.05)$, but there were no differences in inotrope use (table 2). There was a tendency for MBP over the first 24 hours to be lower in infants who developed IVH but the overlap between groups was wide and the differences were not significant (table 3 ).

Infants with grade $3 / 4 \mathrm{IVH}$ had significantly lower median RVO than the other two groups $(P<0.03)$ (table 4). The differences in LVO were not significant. Both the infants with grade 1/2 IVH and those with grade $3 / 4$ IVH had a significantly larger median PDA diameter and higher calculated cross-sectional area $\left(\pi r^{2}\right)$ than those with no IVH $(P<0.006)$.

Stepwise logistic regression analysis was performed to determine factors associated with IVH (all grades). Independent variables tested were gestation, any antenatal steroids, lowest 
Table 3 Variables of mean blood pressure during first 24 hours according to grade of IVH (values are medians and range or percentage)

\begin{tabular}{|c|c|c|c|}
\hline & No IVH $(n=86)$ & $\underset{(n=21)}{\text { Grade } 1 / 2 I V H}$ & $\begin{array}{l}\text { Grade 3/4 IVH } \\
(n=10)\end{array}$ \\
\hline $\begin{array}{l}\text { Mean MBP }(\mathrm{mm} \mathrm{Hg}) \\
\text { Lowest MBP }(\mathrm{mm} \mathrm{Hg}) \\
\% \text { time MBP }<30 \mathrm{~mm} \mathrm{Hg} \\
\text { Variation in } \mathrm{MBP}(\mathrm{SD} / \text { mean } \times \\
\quad 100)\end{array}$ & $\begin{array}{l}33(20-45) \\
25(13-40) \\
17(0-95) \\
11 \%(3.5-27)\end{array}$ & $\begin{array}{l}31(25-49) \\
22(10-35) \\
28(0-100) \\
12 \%(6-28)\end{array}$ & $\begin{array}{l}30(22-38) \\
22.5(14-32) \\
27.5(0-100) \\
16 \%(6-23)\end{array}$ \\
\hline
\end{tabular}

MBP on day 1 , day 1 averaged MAP, treatment with surfactant, volume of plasma expanders given, postnatal age at echocardiography, RVO, PDA diameter, atrial shunt diameter and LVO. Lack of antenatal steroids $(\mathrm{P}=0.006)$ and larger PDA diameter $(\mathrm{P}=0.023)$ were associated with IVH. Additional logistic regression analysis was done, using the same variables, to determine which factors were associated with grade 3 or $4 \mathrm{IVH}$ when compared with infants with no IVH or grades 1 and 2 IVH. Lack of antenatal steroids $(P=0.0015)$ and lower RVO $(P=0.026)$ were associated with grade 3 or 4 IVH.

Twenty seven of the 31 infants who developed an IVH had an head ultrasound scan at the time of echocardiography. Of these, eight had early evidence of IVH and 19 were normal. The cardiac findings in the 19 babies where the IVH occurred after the echocardiogram were then analysed. Table 5 shows larger differences in both median RVO and PDA diameter with more severe IVH, although numbers in the grade $3 / 4$ group were small. RVO in those with grade 3 and $4 \mathrm{IVH}$ was significantly lower than those with no IVH $(P=0.03)$. But the difference with grades 1 and 2 IVH did not quite reach significance $(P=0.07)$. PDA diameter was significantly larger in both groups with IVH than those with no IVH $(P=0.03)$.

\section{Discussion}

In the newborn beagle puppy model, provocation of an IVH requires severe exsanguination followed by reperfusion. ${ }^{11}$ Thus cerebral hypoperfusion seems to be an important antecedent to IVH. That this is also true in preterm infants is suggested by the fact that early systemic hypotension ${ }^{1-3}$ and lower cerebral blood flow $^{45}$ are both risk factors for IVH. Thus an understanding of the causes of

Table 4 Early echocardiographic measurements according to grade of IVH (values are medians and range or percentage)

\begin{tabular}{|c|c|c|c|}
\hline & No IVH $(n=86)$ & $\begin{array}{l}\text { Grade } 1 / 2 I V H \\
(n=21)\end{array}$ & $\begin{array}{l}\text { Grade } 3 / 4 \text { IVH } \\
(n=10)\end{array}$ \\
\hline Age at scan (hours) & $20(7-31)$ & $19(7-23)$ & $14(10-25)$ \\
\hline $\mathrm{RV}$ output $\mathrm{mls} / \mathrm{kg} /$ hour & $203+(70-412)$ & $196^{\star}(66-398)$ & $161 \dagger^{\star}(62-287)$ \\
\hline LV output mls/kg/hour & $211(93-505)$ & $225(82-381)$ & $180(87-400)$ \\
\hline PDA diameter (mm) & $1.0 t^{\star}(0-3.4)$ & $1.5+(0-3.2)$ & $1.6^{\star}(0-2.7)$ \\
\hline $\begin{array}{l}\text { Calculated PDA cross-sectional } \\
\text { area }\left(\pi r^{2}\right)\end{array}$ & $0.8 \dagger^{\star}(0-9.1)$ & $1.8+(0-8.0)$ & $2.0 \star(0-5.7)$ \\
\hline \multicolumn{4}{|l|}{ PDA shunt direction: } \\
\hline Left to right & $74 \%$ & $61 \%$ & $66 \%$ \\
\hline Bidirectional & $25 \%$ & $33 \%$ & $33 \%$ \\
\hline Right to left & $1 \%$ & $6 \%$ & $0 \%$ \\
\hline Atrial shunt diameter (mm) & $2.8(0-4.9)$ & $3.0(0-4.6)$ & $3.3(0-4.5)$ \\
\hline \multicolumn{4}{|l|}{ Atrial shunt direction: } \\
\hline Left to right & $16 \%$ & $25 \%$ & $25 \%$ \\
\hline Bidirectional & $80 \%$ & $70 \%$ & $75 \%$ \\
\hline Right to left & $4 \%$ & $5 \%$ & $0 \%$ \\
\hline
\end{tabular}

^ and + mark significant differences between two groups, $P<0.05$. cerebral hypoperfusion is fundamental to the haemodynamic basis of IVH. As preterm babies are not usually hypovolaemic, ${ }^{1213}$ other causes of low systemic flow are likely to be important.

As far as we are aware, this study is the first to have associated detailed early cardiovascular haemodynamics with IVH and to have shown three significant factors associated with IVH: lack of antenatal steroids and two cardiovascular factors which relate to low systemic blood flows-lower RVO and a larger diameter ductus arteriosus. This study is limited by the fact that, although the echocardiograms were done early, they were not early enough to define the antecedent haemodynamics of IVH in all cases. Eight of 27 babies scanned at the time of echocardiography already had evidence of IVH. As such, the echocardiographic findings in these babies must be seen as pointers to what might be happening in the first few hours after birth. However, when the analysis included only the babies where the IVH occurred after the early scan, the trend to lower RVO and larger PDA diameter becomes more pronounced, although small numbers do limit the statistical power of this subanalysis.

This study provides further confirmation of the protective effect of antenatal steroids against IVH that has been shown in other studies. $^{14}$ Could this protection be mediated through cardiovascular factors? Antenatal steroids reduce the incidence of PDA, ${ }^{15}$ hypotension, and the need for blood pressure support, ${ }^{14}$ and early low blood pressure has been associated both with large PDA shunts ${ }^{1617}$ and with the development of IVH..$^{1-3}$

An association between PDA and IVH has been reported in studies which have defined PDAs by later clinical diagnosis and need for treatment. $^{1819}$ While this does not take into account the haemodynamic influence of the ductus in the early postnatal period when most IVH occur, $80 \%$ of PDAs which become symptomatic will have been large, haemodynamically important, and clinically silent in the early postnatal period. ${ }^{2021}$ In contrast, neither Shortland et al ${ }^{7}$ nor Ment et al ${ }^{22}$ showed any association between IVH and early PDA. However, neither study used echocardiographic measures which would define PDA haemodynamic importance. Most ducts will be open in the early postnatal period, ${ }^{20}$ but haemodynamic importance varies widely and so too could the influence on outcomes. This study, using a continuous variable which relates to PDA shunt size, ${ }^{9}$ has shown a significant association between PDA diameter and IVH. Left to right flow at ductal level shunts blood away from the systemic circulation, even at this early postnatal time ${ }^{10}$ and it is possible that cerebral hypoperfusion could result. ${ }^{23-25}$ Other evidence which might implicate early PDA shunting in IVH includes the observation that high concentrations of vasodilating prostaglandins have been found both in babies with $\mathrm{IVH}^{26}$ and in those with PDAs, ${ }^{27}$ and also that the prostaglandin inhibitors, indomethacin and ethamsylate, reduce the incidence of both IVH and PDAs when given prophylactically. ${ }^{22} 28$ 
Table 5 Early echocardiographic measurements according to grade of IVH excluding infants with evidence if IVH at the time of echocardiography(values are medians and range or percentage)

\begin{tabular}{llll}
\hline & No IVH $(n=86)$ & $\begin{array}{l}\text { Grade 1/2 IVH } \\
(n=15)\end{array}$ & $\begin{array}{l}\text { Grade 3/4 IVH } \\
(n=4)\end{array}$ \\
\hline $\begin{array}{llll}\text { Age at scan (hours) } \\
\text { RVO mls/kg/hour }\end{array}$ & $20(7-31)$ & $20(7-23)$ & $16(12-20)$ \\
LVO mls/kg/hour & $203(70-412)^{\star}$ & $177(66-286)$ & $131^{\star}(69-172)$ \\
PDA diameter (mm) & $211(93-505)$ & $205(82-381)$ & $206(137-317)$ \\
$\begin{array}{l}\text { Calculated PDA cross-sectional area } \\
\quad\left(\pi \mathrm{r}^{2}\right)\left(\mathrm{mm}^{2}\right)\end{array}$ & $1.0 \dagger^{\star}(0-3.4)$ & $1.5 \dagger^{\star}(0-3.2)$ & $2.3^{\star}(2-2.7)$ \\
Atrial shunt diameter (mm) & $2.8(0-4.1)$ & $1.8 \dagger^{\star}(0-8.0)$ & $4.2^{\star}(3.1-5.7)$ \\
\hline
\end{tabular}

$\star$ and $\dagger$ mark significant differences between two groups, $\mathrm{P}<0.05$.

Low RVO was the additional factor associated with grade 3 and $4 \mathrm{IVH}$ in our study. RVO is probably a more sensitive measure of low systemic blood flow than $\mathrm{LVO}^{10}$ because, while neither ventricular output represents systemic blood flow due to intracardiac shunting, the atrial shunts which increase RVO are usually smaller than PDA shunts which increase LVO. In our previous report, the two significant negative influences on RVO were PDA shunt size and MAP. These factors (and probably others which we have not been able to define) may combine to produce a low systemic flow state which makes the brain vulnerable to haemorrhage when reperfusion occurs.

Prevention of IVH remains an elusive goal. Early use of prophylactic indomethacin seems to reduce the incidence of IVH ${ }^{22}$ and the results of this study would suggest that some of this effect could be mediated through ductal closure. However, concerns about the negative effects of indomethacin on cerebral blood flow and oxygenation have led to cautions against the use of this approach.$^{29}$ If IVH risk is associated with early PDA size or other cardiovascular factors which could be recognised using echocardiography then it might be possible to target indomethacin and other measures to support the systemic circulation at just those at risk infants. We are currently undertaking a prospective study of cardiovascular and cerebral haemodynamics starting in the first hours after birth to explore this possibility.

1 Miall Allen VM, de Vries LS, Whitelaw AG. Mean arterial blood pressure and neonatal cerebral lesions. Arch Dis Child 1987;62:1068-9.

2 Bada HS, Korones SB, Perry EH, Arheart KL, Ray JD, Pourcyrous $M$, et al. Mean arterial blood pressure changes in premature infants and those at risk for intraventricular in premature infants and those at risk for

3 Watkins AM, West CR, Cooke RW. Blood pressure and cerebral haemorrhage and ischaemia in very low birthweight ebral haemorrhage and ischaemia in very

4 Ment LR, Duncan CC, Ehrenkranz RA, Lange RC, Taylor $\mathrm{KJ}$, Kleinman CS, et al. Intraventricular hemorrhage in the preterm neonate: timing and cerebral blood flow changes. f Pediatr 1984;104:419-25.
5 Lou HC, Skov H, Pederson H. Low cerebral blood flow: A risk factor in the neonate. $\mathcal{F}$ Pediatr 1979;95:606-9.

6 Perlman JM, Hill A, Volpe JJ. The effect of patent ductus arteriosus on flow velocity in the anterior cerebral arteries: Ductal steal in the premature newborn infant. $\mathcal{f}$ Pediat 1981;99:767-71.

7 Shortland DB, Gibson NA, Levene MI, Archer LN, Evan DH, Shaw DE. Patent ductus arteriosus and cerebral circulation in preterm infants. Dev Med Child Neurol 1990;32:386-93.

8 Evans N, Iyer P. Incompetence of the foramen ovale in preterm infants supported by mechanical ventilation. $\mathcal{F}$ Pediat 1994;125:786-92.

9 Evans N, Iyer P. Assessment of ductus arteriosus shunt in preterm infants supported by mechanical ventilation: effect of interatrial shunting. $\mathcal{F}$ Pediatr 1994;125:778-85.

10 Evans N, Kluckow M. Early determinants of right and left ventricular output in ventilated preterm infants. Arch Dis Child 1996;74:F88-94.

11 Ment LR, Stewart WB, Duncan CC, Lambrecht R. Beagle puppy model of intraventricular hemorrhage. 7 Neurosur gery 1982;57:219-23.

12 Barr PA, Bayley PE, Sumners J, Cassady G. Relation between arterial blood pressure and blood volume and effect of infused albumin in sick preterm infants. Pediatrics 1977;60:282-9.

13 Bauer K, Linderkamp O, Versmold HT. Systolic blood pressure and blood volume in preterm infants. Arch Dis Child 1993;69:521-2.

14 Garland JS, Buck R, Leviton A. Effect of materna glucocorticoid exposure on risk of severe intraventricular hemorrhage in surfactant-treated preterm infants. $₹$ Pediatr 1995;126:272-9.

15 Morales WJ, Angel JL, O'Brien WF, Knuppel RA. Use of ampicillin and corticosteroids in premature rupture of membranes: $a$

16 Evans N, Moorcraft J. Effect of patency of the ductus arteriosus on blood pressure in very preterm infants. Arch $D i$ Child 1992;67:1169-73.

17 Knight DB. Patent ductus arteriosus: how important to which babies? Early Hum Dev 1992;29:287-92.

18 Dykes D, Lazzara A, Ahmann P, Blumenstein B, Schwartz J Brann A. Intraventricular hemorrhage: $A$ prospective Brann A. Intraventricular hemorrhage: A prospecti

19 Perlman JM, Rollins N, Burns D, Risser R. Relationship between periventricular intraparenchymal echodensities and germinal matrix-intraventricular hemorrhage in the very low birth weight neonate. Pediatrics 1993;91:474-80.

20 Evans N, Iyer P. Longitudinal changes in the diameter of the ductus arteriosus in ventilated preterm infants: correlation with respiratory outcomes. Arch Dis Child 1995;72:F15661.

21 Kluckow M, Evans N. Early echocardiographic prediction of symptomatic patent ductus arteriosus in ventilated preof symptomatic patent ductus arterios

22 Ment LR, Oh W, Ehrenkranz RA, Philip AG, Vohr B, Allan $\mathrm{W}$, et al. Low-dose indomethacin and prevention of intra $\mathrm{W}$, et al. Low-dose indomethacin and prevention of intraventricular hemorrhage: a
Pediatrics 1994;93:543-50.

23 Shimada S, Kasai T, Konishi M, Fujiwara T. Effects of patent ductus arteriosus on left ventricular output and organ blood flows in preterm infants with respiratory distress syndrome treated with surfactant. F Pediatr 1994;125:270

24 Mellander M, Larsson LE. Effects of left-to-right ductus shunting on left ventricular output and cerebral blood flow velocity in 3-day-old preterm infants with and without velocity in 3-day-old preterm infants with and

25 Clyman RI, Mauray F, Heymann MA, Roman C. Cardiovascular effects of patent ductus arteriosus in preterm vascular effects of patent ductus arteriosus in preterm

26 Hutchison AA, Ogletree ML, Palme CJ, Leheup BP, Barret $\mathrm{JM}$, Fleischer AC, et al. Plasma 6-keto prostaglandin F1 alpha and thromboxane B2 in sick preterm neonates. Prostaglandins Leuk Med 1985;18:163-81.

27 Hammerman C, Strates E, Valaitis S. The silent ductus: its precursors and its aftermath. Pediatr Cardiol 1986;7:121-7.

28 Amato M, Huppi P, Markus D. Prevention of symptomatic patent ductus arteriosus with ethamsylate in babies treated patent ductus arteriosus with ethamsylate in babies

29 Reynolds EO, Meek J. Prevention of periventricular hemorrhage. Pediatrics 1994;93:677-9. 